\title{
A study of correlation of use, citation and publishing of journal papers by Indian space technologists
}

\section{S Sridhar}

ABSTRACT: Patterns of the publishing of papers in journals by Indian space technologists and their use and citation were studied. Pearson correlation coefficient has been calculated to find out the correlation and to test the null hypothesis that there is no correlation among publishing in journals, citing from journals and use of journals by a defined set of researchers. A slight positive correlation between citing from journals and publishing in journals is indicated by the study. It is concluded that a more tightly controlled study with a larger and homogenous sample might result in a better correlation.

KEYWORDS: Use studies, citation studies, publishing pattern, Indian space technologists, correlation studies

\section{INTRODUCTION}

Journals are the formal primary medium of communication for researchers. The cycle of information consumption, transmission and production is complex. Journals alone cannot represent all phases of the cycle. Nevertheless, the role of journals in information gathering, use and transmission by researchers cannot be over estimated. The interactions of Indian space technologists with journals in terms of usage, citation and publishing papers are examined in this case study to explore possible correlations among these factors. The null hypothesis could be stated as that there is no correlation among these variables other than those attributable to chance.

\section{BACKGROUND OF THE STUDY}

As part of a comprehensive user study ${ }^{1}$, about 800 defined sets of users of the Indian Space Research Organisation Satellite Centre (ISAC) Library were asked for the number of papers they have published. Out of 489 respondents, only 93 persons (mostly scientists and engineers 
A study of correlation of use, citation and publishing of journal papers by Indian space technologists

at fairly higher and middle levels) have one or more papers to their credit. When followed up, 224 actual references were made available. However, it was possible to obtain copies of 148 papers published over the last decade. Ignoring conference papers and a few unspecified papers, 85 journal articles were selected for this study.

These 85 sample papers, ${ }^{2}$ in which at least one of the authors is from ISAC, were published in 31 journals, and they in turn cited 432 articles from 90 journals, apart from books, reports and conference papers. Twenty-four journals were common to both publishing and citing activities. In other words, there were 97 distinct journals that covered all of the source articles and cited articles. It may be noted here that 28 of the 31 journals in which Indian space technologists published papers and 69 of the 90 journals from which citations were made by them are subscribed to by ISAC library.

Subsequently a use study ${ }^{3}$ of 485 current journals subscribed to by the library was carried out and use data available to the extent of 68 of the above referred 97 journals extracted. In the use study, two latest issues of current journals were monitored for about three months from the date of their first display in the library to record the number of in-house uses as well as lentout uses. In the case of in-house use, a maximum of four in-house uses a day was recorded for a single issue of a journal.

The data collected on these three variables of journals were tabulated to calculate the Pearson correlation coefficient and to test the significance of the coefficient through the t-test.

\section{LIMITATIONS OF THE STUDY}

This study has some limitations. Firstly, the sample journal articles of Indian space technologists were not systematically drawn. All reprints made available by the authors were considered. Secondly, quite a few co-authors of these papers are from outside ISAC. Thirdly, it is not certain that all these papers are the results of work done by researchers at their present place of work, i.e., ISAC. Fourthly, journal use data is not restricted only to authors of sample papers, but it also present consolidated use of journals by all the users of ISAC Library. Owing to certain practical difficulties segregation of journal use data of ISAC authors could not be done. Fifthly, the variables of use, citation and publishing of papers in journals could not be well controlled. For example, ISAC authors could use journals other than those subscribed to by ISAC library by ordering preprints, reprints, visiting other libraries, etc., and hence cite these in their papers. Further, the use study was carried out during September 1983 and March 1984, 
whereas the sample papers were published during the decade prior to the use study. Above all, use studies and citation studies are themselves imbued with certain drawbacks and presumptions. Lastly the Pearson correlation coefficient was chosen for this study on the assumption that variables are distributed normally.

\section{CALCULATION OF CORRELATION COEFFICIENT}

The following formulae are used for calculating the Pearson correlation coefficient and t-test value:

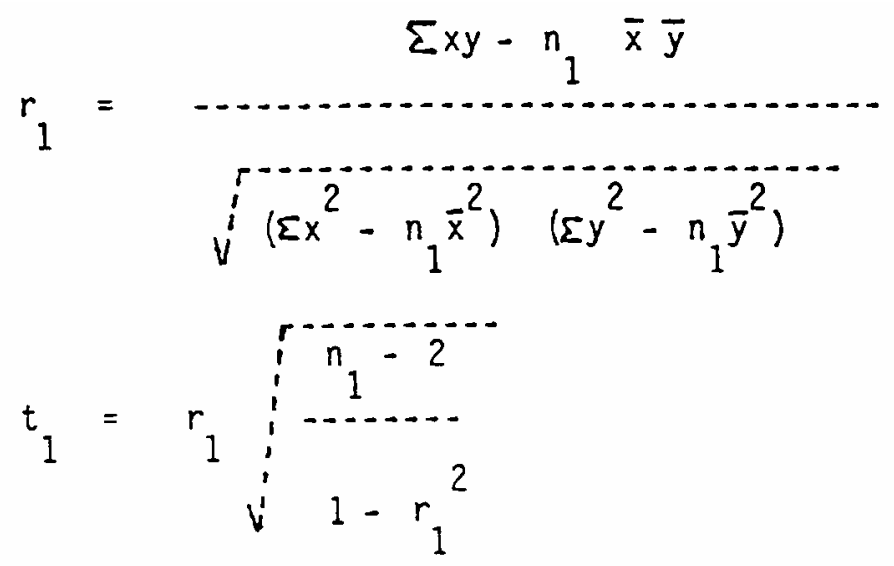

\section{Where,}

$x$ - Number of times two issues of a journal are used in first three months

$y$ - Number of articles published in a journal

$z$ - Number of articles cited from a journal

$r_{1}$ - Pearson correlation coefficient between $x$ and $y$

$r_{2}$ - Pearson correlation coefficient between $y$ and $z$

$r_{3}$ - Pearson correlation coefficient between $x$ and $z$

$\bar{x}$ - Average number of times two issues of a journal are used in the first three months

$\bar{y}$ - Average number of articles of Indian space technologists published in a journal

$\bar{z}$ - Average number of articles cited by Indian space technologists from a journal

$n_{1}$ - Number of journals observed for $r_{1}$

$n_{2}$ - Number of journals observed for $r_{2}$ 
$n_{3}$ - Number of journals observed for $r_{3}$

$t_{1}$ - $t$-test value of $r_{1}$

$t_{2}$ - $t$-test value of $r_{2}$

$t_{3}-t$-test value of $r_{3}$

$p$ - Significance level as per t-test

$d f$ - Degrees of freedom

The calculated value of $r_{1}$ is as follows:

$$
r_{1}=0.0144 ; p>0.10 ; d f=66
$$

The value of $r_{1}$ is negligible. Hence the null hypothesis that there is no correlation between use of journals and choosing journals for publishing papers by Indian space technologists is valid.

Similarly, we find,

$$
r_{2}=0.1918 ; p<0.05 ; d f=95
$$

For a significant correlation to exist between two variables, the value of the Pearson correlation coefficient would normally be \pm 0.4 or more. Thus the $r_{2}$ indicates a slight positive correlation between choice of a journal for publishing papers and citing papers. However, the value of $t_{2}$ at 95 degrees of freedom in the t-distribution table indicates that the calculated value of $r_{2}$ is different from zero at 0.05 significance level. Hence, we may conclude that a slight positive correlation exists between publishing in and citing from journals. The null hypothesis that there is no correlation between citing from journals and publishing in journals by Indian space technologists may not be true, though not significantly disproved.

Thirdly,

$$
r_{3}=0.0055 ; p>0.10 ; d f=66
$$

The value of $r_{3}$ is close to zero, and hence the variables in use of a journal and choice of the same for citing by Indian space technologists are independent. In other words, the null hypothesis here is found valid. 


\section{DISCUSSION}

It is but natural that researcher gathers and consumes more information than what he or she transmits, cites, generates and publishes. The variable use of a journal is very much constrained by the 'law of least effort,' and an average researcher would like to use as many potentially useful journals in his or her field as possible. On the other hand, when publication of paper is desired, he or she prefers a journal considered more relevant and reputed than others. While use of a journal is constrained by factors such as availability and access, choosing a journal for publishing is restricted by the capability to meet the expectations of the journal. But it is partly obvious that a researcher chooses a journal when publishing that he or she at least occasionally uses. The converse is not always true. As such, no correlation between use of a journal and choosing the same for publishing is found in this study. This is in conformity with an earlier finding of the American Psychological Association. ${ }^{4}$

A slight positive correlation between choice of a journal for publishing papers and citing papers by Indian space technologists is found in spite of the fact that the general rule is to publish more often in local journals and cite more often from foreign journals. Though citation studies have some limitations, it is believed that an article cited is very much used by the researcher and found relevant to his or her work. This correlation is not totally unexpected as the majority of publishing and citing activities take place within a set of journals in the field.

Lastly, the use of a journal and the chance of its being cited have not demonstrated significant correlation. However, a study by Mendez and Blanco ${ }^{5}$ revealed that the most cited journals by a group of dairy research scientists corresponded well with the most requested journals at their library. As mentioned earlier, citing of a journal almost implies use but not necessarily viceversa. In other words, one of the major reasons for lack of correlation in this study is that the number of journal articles that a researcher uses is very much larger than that cited. Thus, by restricting the use study to only journals from which sample papers are cited and to those authors who have cited, a better correlation of these two factors can be expected.

\section{CONCLUSION}

The present study with the limitations inherent in incidental use of data from a larger study has shown a slight positive correlation between publishing in and citing from a journal. A third variable use of journals is found to be independent of publishing and citing. It is greatly desirable to have a more tightly controlled experiment with a larger sample and preferably a 
A study of correlation of use, citation and publishing of journal papers by Indian space technologists

homogeneous user group as well as journals in a specific subject area to test the hypothesis. Alternatively, an opinion survey of such a user group about journals in their area might also result in a more accurate picture of what is happening.

\section{REFERENCES}

1. M. S. Sridhar. A study of information seeking behaviour of space technologists with emphasis on correlating user characteristics with such behaviour. Ph.D. Thesis. (Mysore : University of Mysore, 1987).

2. ------------. "Citing patterns of Indian space technoligsts," International Library Review, 17(3) July 1985, 259-274.

3. ----------. "Use of current journals by Indian space technologists," Serials Librarian, 10(3) Spring 1986, 77-93.

4. A. J. Meadows. Communication in Science. (London : Butterworths, 1974) p105.

5. A. Mendez and C. Blanco. "Differences between requested and cited literature in a group of dairy research scientists, "Journal of Information Science, 1, 1979, 113-116.

"Collection Management 12 (1/2) $1990:$ 147-152.

\section{About the Author}

Dr. M. S. Sridhar is a post graduate in Mathematics and Business Management and a Doctorate in Library and Information Science. He is in the profession for last 36 years. Since 1978, he is heading the Library and Documentation Division of ISRO Satellite Centre, Bangalore. Earlier he has worked in the libraries of National Aeronautical Laboratory (Bangalore), Indian Institute of Management (Bangalore) and University of Mysore. Dr. Sridhar has published 4 books, 83 research articles, 22 conferences papers, written 19 course

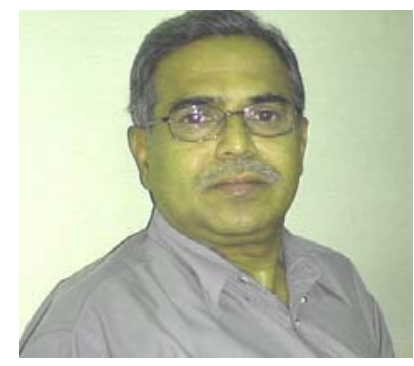
materials for BLIS and MLIS, made over 25 seminar presentations and contributed 5 chapters to books.

E-mail: sridharmirle@yahoo.com, mirlesridhar@gmail.com, sridhar@isac.gov.in ; Phone: 9180-25084451; Fax: 91-80-25084476. 